\title{
Airway management in personal protective equipment conditions
}

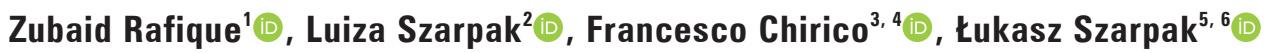 \\ 'Henry JN Taub Department of Emergency Medicine, Baylor College of Medicine, Houston, TX, United States \\ ${ }^{2}$ Institute of Outcomes Research, Polonia University, Częstochowa, Poland \\ ${ }^{3}$ Post-graduate School of Occupational Health, Università Cattolica del Sacro Cuore, Roma, Italia \\ ${ }^{4}$ Health Service Department, Italian State Police, Ministry of the Interior, Milano, Italy \\ ${ }^{5}$ Institute of Outcomes Research, Maria Sklodowska-Curie Medical Academy, Warsaw, Poland \\ ${ }^{6}$ Maria Skłodowska-Curie Białystok Oncology Center, Białystok, Poland
}

\section{To the Editor}

Airway management is one of the key skills that medical personnel should master, especially by emergency medical service teams. As shown by many studies, the effectiveness of endotracheal intubation in emergency medicine conditions is insufficient, ranging from $57.6 \%$ to $89.9 \%$ [1, 2]. However, in the situation of the current SARSCoV-2 pandemic, medical personnel should treat each patient in pre-hospital conditions as a potentially infected patient, therefore they should perform medical procedures wearing personal protective equipment (PPE) for aerosol generating procedures (AGPs) [3, 4].

It is problematic that PPE-AGP, by limiting movement and visibility, may reduce the effectiveness of individual medical procedures and extend their time [5]. Maslanaka et al. in his meta-analysis he showed that anaesthesiologists wearing PPE-AGP could intubate patients more efficiently with the AirTraq videolaryngoscope compared to the Macintosh laryngoscope (85.6\% vs $68.4 \% ; p=0.006$ ) [6]. However, because of the lack of commonly available videolaryngoscopes in prehospital care conditions, alternative methods of securing the airways to direct laryngoscopy, including new types of laryngoscopes (i.e. Vie Scope ${ }^{\circledR}$, or the use of supraglottic ventilation devices), are worth considering [7].

Ladny et al. stated in his study that blind intubation is highly effective when using the iGel mask and the laryngeal mask, as a guide for the endotracheal tube [8]. Therefore, it is worth considering this method of intubation in the conditions of using PPE-AGP because it does not require such specialized skills as direct laryngoscopy from the operator. Nevertheless, it is necessary to conduct a study confirming the usefulness of this method of endotracheal intubation in the aspect of patients with suspected SARS-CoV-2.

In summary, thanks to the development of medical technology, there is a wide range of respiratory protection methods alternative to direct laryngoscopy, which medical personnel should use when securing a patient with suspected or confirmed SARS-CoV-2.

\section{Conflict of interest}

None declared.

\section{References:}

1. Sakles JC, Mosier JM, Patanwala AE, et al. The Utility of the C-MAC as a Direct Laryngoscope for Intubation in the Emergency Department. J Emerg Med. 2016; 51(4): 349-357, doi: 10.1016/i.jemermed.2016.05.039, indexed in Pubmed: 27471132.

2. Mallick T, Verma A, Jaiswal S, et al. Comparison of the time to successful endotracheal intubation using the Macintosh laryngoscope or KingVision video laryngoscope in the emergency department: A prospective observational study. Turk J Emerg Med. 2020; 20(1): 22-27, doi: 10.4103/2452-2473.276381, indexed in Pubmed: 32355898.

3. Dzieciatkowski T, Szarpak L, Filipiak KJ, et al. COVID-19 challenge for modern medicine. Cardiol J. 2020; 27(2): 175-183, doi: 10.5603/CJ.a2020.0055, indexed in Pubmed: $\underline{32286679}$.

4. Chirico F, Nucera G, Sacco A, et al. Proper respirators use is crucial for protecting both emergency first aid responder and casualty from COVID-19 and airborne-transmitted infections. Adv Respir Med. 2021; 89(1): 99-100, doi: 10.5603/ARM. a2021.0028, indexed in Pubmed: 33660253.

5. Malysz M, Dabrowski M, Böttiger BW, et al. Resuscitation of the patient with suspected/confirmed COVID-19 when wearing personal protective equipment: A randomized multicenter crossover simulation trial. Cardiol J. 2020; 27(5): 497-506, doi: 10.5603/CJ.a2020.0068, indexed in Pubmed: 32419128.

6. Maslanka M, Smereka J, Pruc M, et al. Airtraq ${ }^{\circledR}$ versus Macintosh laryngoscope for airway management during general anesthesia: A systematic review and meta-analysis of randomized controlled trials. Disaster and Emergency Medicine Journal. 2021, doi: 10.5603/demj.a2021.0001. 
7. Maslanka M, Smereka J, Czyzewski L, et al. VieScope ${ }^{\circledR}$ laryngoscope versus Macintosh laryngoscope during difficult intubation performed by paramedics: a randomized cross-over manikin trial. Disaster and Emergency Medicine Journal. 2020, doi: 10.5603/demj.a2020.0031.
8. Ladny JR, Bielski K, Szarpak L, et al. Are nurses able to perform blind intubation? Randomized comparison of I-gel and laryngeal mask airway. Am J Emerg Med. 2017; 35(5): 786-787, doi: 10.1016/j.ajem.2016.11.046, indexed in $\mathrm{Pu}$ bmed: 27899211. 